\title{
CORRELATION BETWEEN SERUM CREATININE \& URINE ALBUMIN IN DIABETIC NEPHROPATHY PATIENTS
}

\author{
SANYAL $M^{1}$, HOSSAIN MZ ${ }^{2}$, KHAN MAU ${ }^{3}$, RAHMAN F ${ }^{4}$, ALI MH ${ }^{5}$
}

\begin{abstract}
Diabetic nephropathy has some distinct stages and each of the stages are individually defined according to different amount of albumin excreted through urine. Serum creatinine is a very common tool of renal assessment in diabetic nephropathy. This study aims at observation of existing correlation between serum creatinine and urine albumin in diabetic nephropathy patients.

This cross sectional observational study has been conducted on 50 diabetic patients admitted to medicine department of Dhaka Medical College Hospital. Patients were included in this study after fulfilling inclusion and exclusion criteria in a period January 2018 to June 2018. After selection, data were collected by structured questionnaire. Then 24 hour urinary total protein, urine for microalbumin, complete blood count, fasting blood sugar, two hours postprandial blood sugar, $\mathrm{HbA1C}$, serum creatinine report were collected and analyzed it with the help of SPSS 16.O MS excel.

Among total 50 patients, 34 patients were diagnosed on the basis of microalbuminuria and the rest were found to have raised urinary total protein. The male patients were 54 percent of the total population. Most of the patients were in between the age of 57 to 67 years. The r value is insignificant in two graphs where serum creatinine was compared with urine microalbumin and serum creatinine respectively, which suggests absence of linear or any other correlation between these two components. The estimated Glomerular Filtration Rate (eGFR) was calculated by MDRD equation individually. Staging was done on the base of eGFR. Only $41.37 \%$ of the patients with microalbuminuria, showed eGFR consistent with its staging while only $31.5 \%$ of the patients with proteinuria showed respective expected eGFR. And the difference between the mean serum creatinine in two groups was insignificant.

This study has shown that, the serum creatinine has no linear correlation with urinary albumin in diabetic nephropathy patients. So, commonly used serum creatinine based formula to calculate the estimated GFR cannot reflect the amount of urinary protein excretion all the time. So it can misinterpret the staging of the disease which can delay the appropriate treatment of the patient.
\end{abstract}

Key Words: Diabetic Nephropathy, Proteinuria, Microalbuminuria, Serum Creatinine

J Dhaka Med Coll. 2018; 27(2) : 141-147

\section{Introduction}

The word "Diabetes" means "passing through", referring to the polyuria, a symptom historically present on those affected by the disease ${ }^{1}$ About $30 \%$ of diabetic patients develops nephropathy after 20 years of diagnosis ${ }^{2}$. The disease is progressive and may cause death in two or three years after the initial diagnosis and is more frequent in men $^{3}$.

The prevalence of diabetes and nephropathy is high in the world as well as in Bangladesh.
Based on 2002 US data, diabetes is the cause of renal disease in $44 \%$ to $45 \%$ of ESRD (end stage renal disease) cases worldwide ${ }^{3}$.About 5.6 $\%$ of the affected population thought to be leading to ESRD and being the cause of morbidity and mortality among diabetic patients in Bangladesh 4 .

The renal hemodynamic abnormality is similar in type 1 and type 2 diabetes $^{5}$. Diabetic nephropathy has several distinct stages of

1. Dr. Mousumi Sanyal, Assistant Professor, Department of Medicine, Dr. Sirajul Islam Medical College, Dhaka

2. Dr. Mohammad Zaid Hossain, Associate Professor, Department of Medicine, Dhaka Medical College Hospital.

3. Dr. Md. Arif Uddin Khan, Junior Consultant, Sarkari Karmachari Hospital, Dhaka

4. Dr. Farzana Rahman, Assistant Professor of Medicine, Dhaka Medical College, Dhaka

5. Dr. Md. Haider Ali, IMO, Department of Medicine, Dhaka Medical College, Dhaka

Correspondence : Dr. Mousumi Sanyal, Contact no-01786520968, Email: mousumi_sanyal85@yahoo.com

Received: 12 July 2018

Revision: 26 August 2018

Accepted: 08 September 2018

https://doi.org/10.3329/jdmc.v27i2.45826 
development. First stage is "Glomerular hyperfiltration". Here functional changes occur in the nephron at the level of the glomerulus, including glomerular hyperfiltration and hyperperfusion, before the onset of any measurable clinical changes (eGFR $>90 \mathrm{ml}$ / $\left.\min / 1.73 \mathrm{~m}^{2}\right)$. The next stage is the "Normal Albuminuria" where the GFR remains elevated but urine albumin expelling is normal and glomerular basement membrane (GBM) thickens as mesangium matrix increases (eGFR $60-89 \mathrm{ml} / \mathrm{min} / 1.73 \mathrm{~m}^{2}$ ) ${ }^{6}$. In the third stage, named as "Incipient stage", there is microalbuminuria; which is the first laboratory marker of the disease. In this stage, the blood pressure will slightly rise (eGFR $30-59 \mathrm{ml} / \mathrm{min} /$ $\left.1.73 \mathrm{~m}^{2}\right)$. A clinically asymptomatic period of decline follows, with progression of microalbuminuria to the next stage of macroalbuminuria or "Overt nephropathy" (eGFR 15-29 $\mathrm{ml} / \mathrm{min} / 1.73 \mathrm{~m}^{2}$ ). Once macroalbuminuria has developed, renal function falls at a significant but variable rate ( potential decline in GFR by $2-2 \mathrm{ml} / \mathrm{min} /$ year). End stage renal disease can be defined when eGFR $<15 \mathrm{ml} / \mathrm{min} / 1.73 \mathrm{~m}^{2}$. ${ }^{6}$

Urine albumin and estimated glomerular filtration rate (eGFR) are the two key markers for chronic kidney disease (CKD) ${ }^{7}$. The other useful investigations tools might be serum Urea, BUN and serum electrolytes. The urine albumin creatinine ration (ACR) is another useful measure of renal function in diabetic renal disease $^{8}$

In case of diabetic kidney disease, an important marker; the eGFR, is calculated from the serum creatinine. But now, researchers say, the use of serum creatinine based formulas to identify the stage of renal impairment in diabetic patients should be questioned ${ }^{9}$.

This study is aiming at finding out a relation between these two markers. It will make a step for future researchers to clear the role of serum creatinine in diabetic nephropathy patient.

GFR can not be measured directly. Rapid estimation of GFR by using creatinine-based mathematical equations is an attractive alternative to the clinician. There are frequent equation available to calculate the GFR from serum creatinine. Among them the MDRD equation is the most reliable one particularly for Caucasian adults ${ }^{10}$.
Various MDRD equations have been published; however, the most widely used equation by the health care community is the abbreviated (fourvariable) MDRD equation, which has been reformulated to be used with a standardized serum creatinine assay .It uses age, the inverse of serum creatinine, gender, and race (African American versus non-African American) ${ }^{11}$.

However, there are few pitfalls of this equation. Firstly, age- and gender-associated differences in creatinine production are proportional to muscle mass, and creatinine generation can vary significantly in a given individual over time when muscle mass changes ${ }^{12,13}$. Creatinine is small, circulates unbound to plasma proteins, and is freely filtered at the glomerulus but undergoes tubular secretion into the urinary space ${ }^{14}$. Tubular secretion of creatinine is not constant and varies, not only within an individual, but between individuals. Further, the proportion of total renal creatinine excretion due to tubular secretion increases with decreasing renal function. Also several substances can interfere with laboratory measurements of creatinine, eg.Glucose, uric acid, ketones, plasma proteins, and cephalosporins etc, ${ }^{15,16}$

For all these reasons, serum creatinine based equations are not truly reliable to measure GFR. Either we should measure GFR directly or we need an exact relation between these two markers.

\section{Methods \& Materials:}

This cross sectional observational study has been conducted on 50 diabetic patients admitted to medicine department of Dhaka Medical College Hospital. Patients were included in this study after fulfilling inclusion and exclusion criteria in a period of 6 months. After selection, data were collected by structured questionnaire. Then 24 hour urinary total protein, urine for microalbumin, complete blood count, fasting blood sugar, two hours postprandial blood sugar, HbA1C, serum creatinine report were collected and analyzed it with the help of SPSS 16.0 MSexcel.

\section{Inclusion criteria}

Patients of diabetic nephropathy evidenced by microalbuminuria or proteinuria.

\section{Exclusion criteria:}

- Patient receiving ACE inhibitor, ARB, Calcium Channel Blocker 
- Hypertension

- SLE

- RA

- UTI

- Fever due to any cause

- Renal impairment due to other cause.

- Pregnancy

- Any serious co-morbid disease (eg$\mathrm{CCF}$,Malignancy)

- Patient unwilling to give consent.

\section{Results}

This observational cross-sectional study was conducted on 50 diabetic nephropathy patients admitted to the Medicine department of Dhaka Medical College Hospital.

Among total 50 patients, 34 patients were included on the basis of urine microalbumin and named as group 1 and the rest 16 patients were included due to protienuria above the physiological range, they were named as group 2 . The serum creatinine was compared with the urine microalbumin and total protein respectively. But no correlation was found (reflected by nonsignificant $r$ value (figure 6 and figure 7 ) . Then, the estimated GFR (eGFR) was measured according to the MDRD equation individualy. The eGFR was used to determine the corresponding staging of the patients (figure 8 and figure 10). According to the definition, staging was compared with the urine protein excretion. Then it was found that, among the group 1 patients, $68 \%$ showed eGFR consistent with its staging (figure 9) while $62 \%$ of the patients of the group 2 showed respective expected eGFR (figure 11). Mean serum creatinine value of both groups were calculated and compared. The difference of the mean serum creatinine was insignificant (figure 12).

\section{Frequency distribution of age among patients}

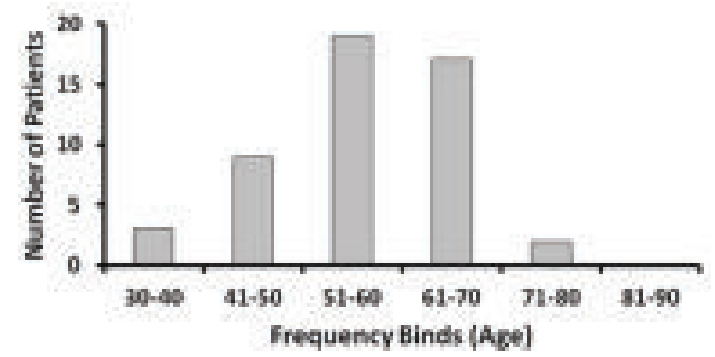

Fig.-1: Distribution of the subjects according to age $(n=50)$

The chart shows that most of the patients were in between the age group of 51 to 70 .

\section{The mean age of the population is 62 years}

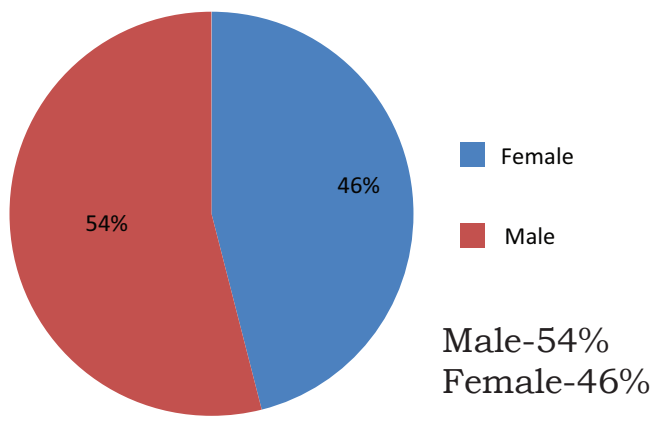

Fig.-2: Distribution of the subjects according to $\operatorname{sex}(n=50)$

The pie chart shows that $54 \%$ of the population were male while the rest $46 \%$ patients were female, which reveals that both sexes are more or less equally affected by the disease.

\section{Table-I}

Distribution of the study patients according to clinical presentation ( $n=50)$

\begin{tabular}{|c|c|c|c|c|c|}
\hline \multirow[t]{3}{*}{ Clinical presentation } & \multirow{2}{*}{\multicolumn{2}{|c|}{$\begin{array}{c}\text { Group I }(\mathrm{n}=34) \\
\text { Microalbuminuria }\end{array}$}} & \multirow{2}{*}{\multicolumn{2}{|c|}{$\begin{array}{c}\text { Group II }(n=16) \\
\text { UTP }\end{array}$}} & \multirow[t]{3}{*}{$\mathrm{p}$ value } \\
\hline & & & & & \\
\hline & $\mathrm{n}$ & $\%$ & $\mathrm{n}$ & $\%$ & \\
\hline Dyspnoea & 2 & 5.88 & 5 & 31.25 & $0.379^{\mathrm{NS}}$ \\
\hline Tingling & 2 & 5.88 & o & 0 & $0.225^{\mathrm{NS}}$ \\
\hline Leg edema & 2 & 5.88 & 5 & 31.255 & $0.379^{\mathrm{NS}}$ \\
\hline Anasarca & o & 0 & 2 & 10 & $0.004^{\mathrm{S}}$ \\
\hline Others & 0 & 0 & 2 & 10 & $0.225^{\mathrm{NS}}$ \\
\hline
\end{tabular}

$\mathrm{S}=$ Not significant

The table describes distribution of the study patients according to the clinical presentation. Both group vary insignificantly according to the symptoms except anasarca. 


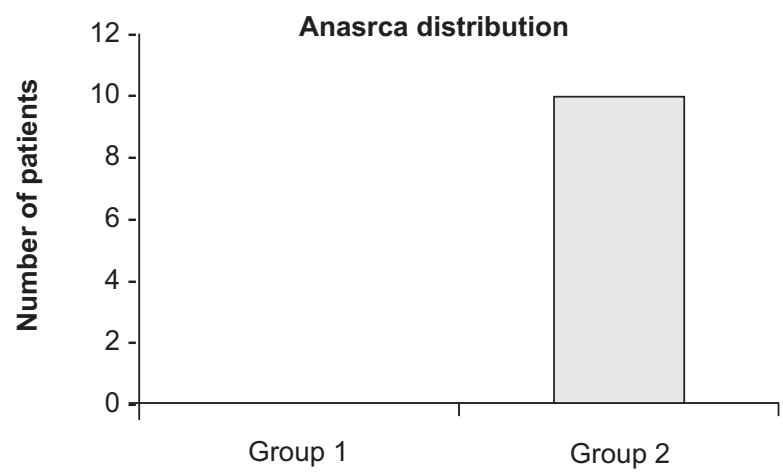

Fig.-4 : Distribution of anasarca among study patients $(n=50)$

From the above data, it is evident that, both of the group significantly differ in the presentation of anasarca, where the $\mathrm{p}$ value is significant .It demonstrates that group 2 patients have more chance to develop anasarca then the other group.

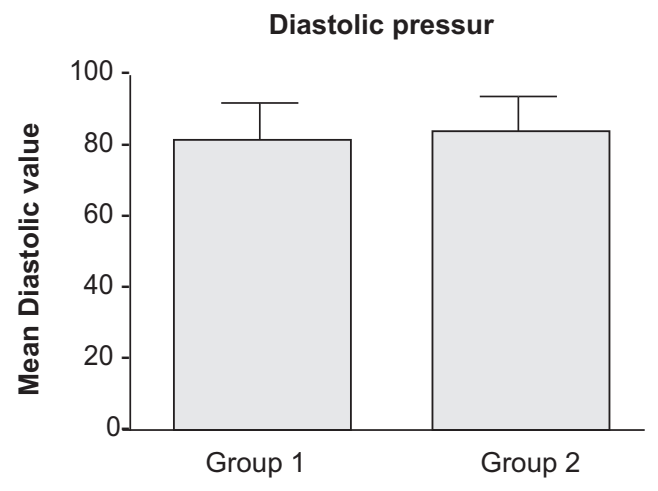

$P$ value is 0.06 that means it is not significant.

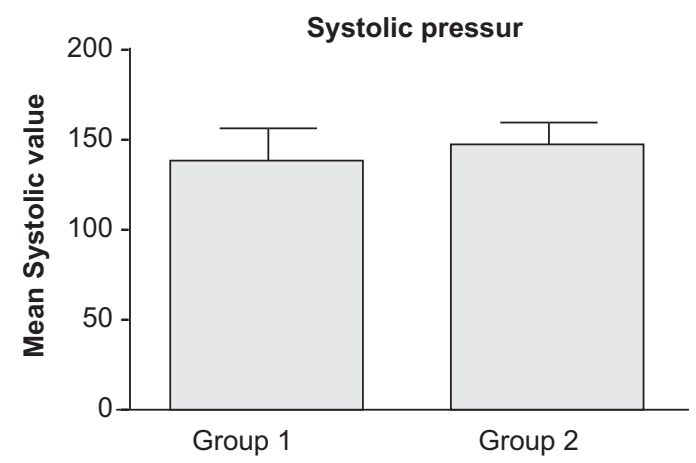

$P$ value is 0.06 that means it is not significant.

Fig.-5: Distribution of the study patients according to $H / O$ Hypertension $(n=50)$
In both groups the blood pressure is above normal limit .P value is not significant.

So, both of the group are equally prone to hypertension.

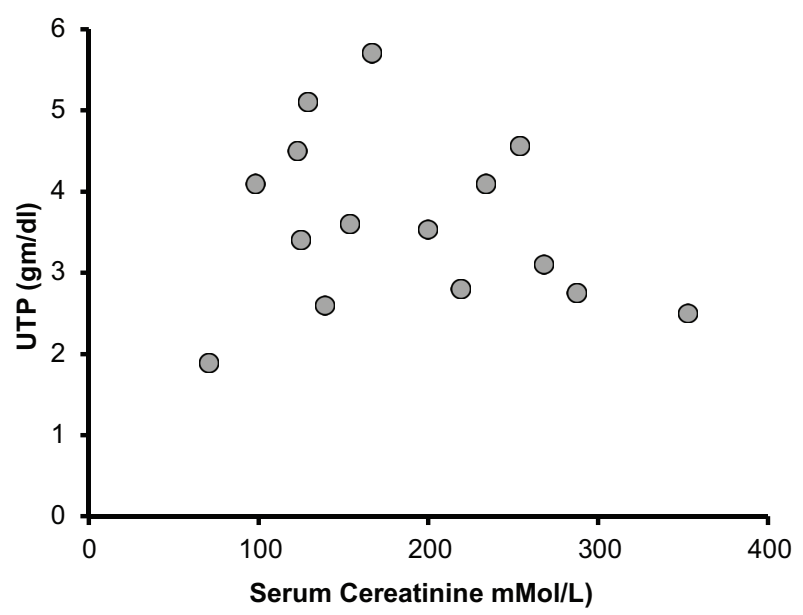

Fig.-6: Correlation between Serum Creatinine and Urine Protein

No apparent correlation was observed between Serum Cereatinine and UTP in the study population. Random distribution of the data points rules out any liner correlation between these two parameter among the 16 patients of Group 2. The value of $r$ is not significant.

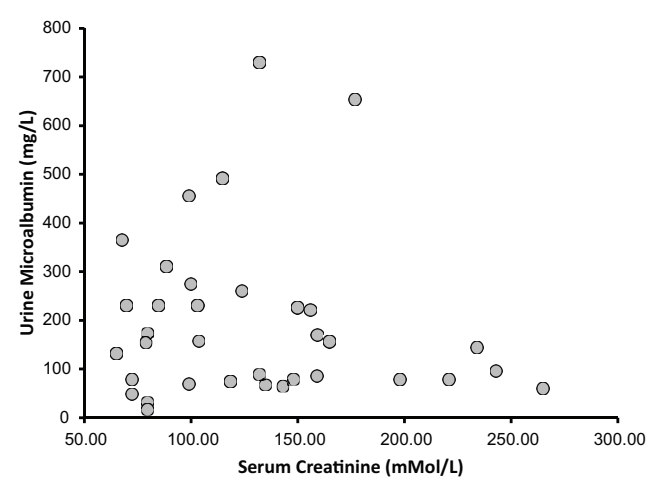

Fig.-7: Correlation between Serum Creatinine and Urine Microalbumin

No significant correlation was observed between Serum Cereatinine and Urine Microalbumin in the study population. Absence of any positive correlation rules out any possibility of linerity betrween these two parameters among 34 patients of group 1. The value of $r$ is not significant. 


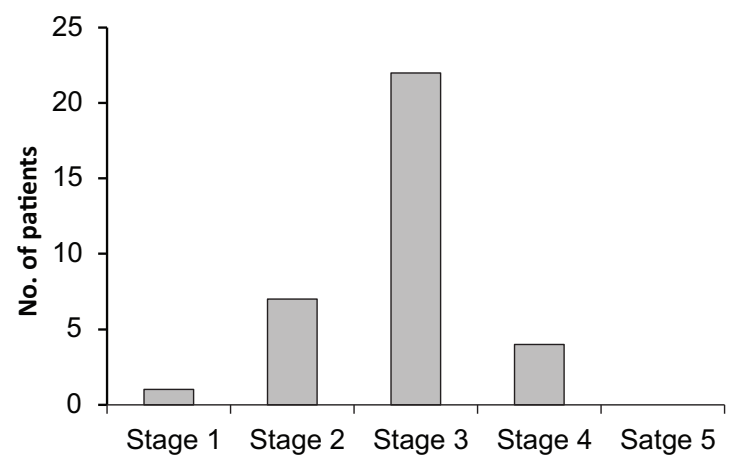

Most of the patients belong to the stage 3 .

Fig.-8: Satging of the group 1 patients based eGFR $(n=34)$

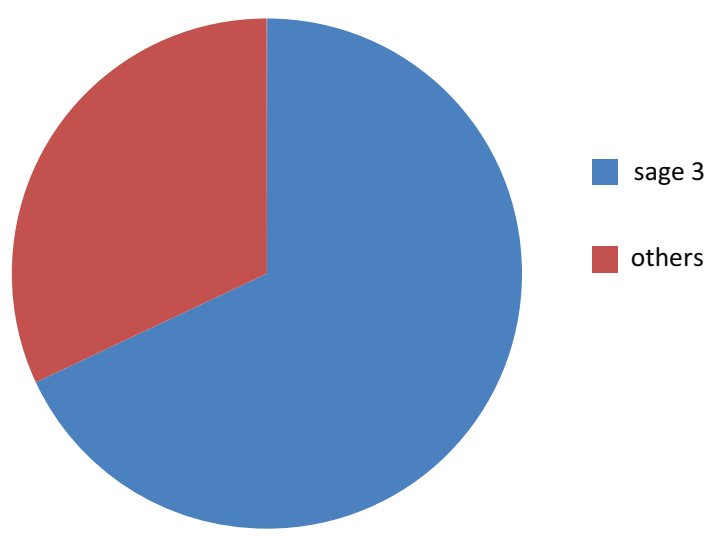

So, the diagram shows that $68 \%$ of the populations belong to the stage 3 and the rest are scattered in different stages.

Fig.-9: Percentage distribution of group 1 patients according to staging

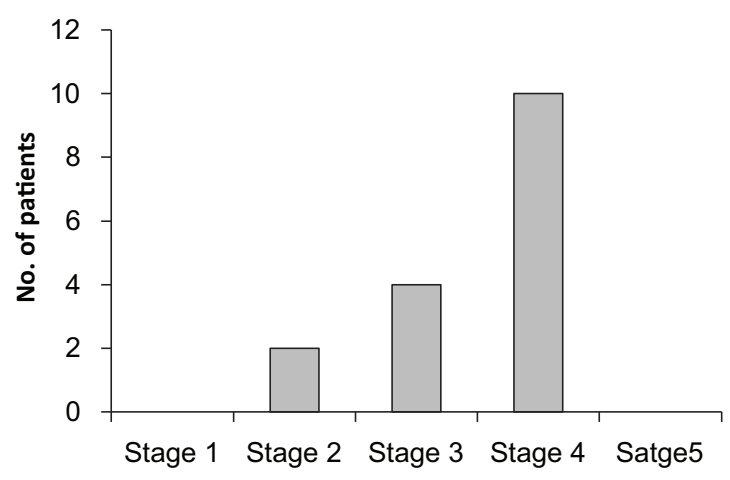

The bar diagram shows maximum of the patients belong to stage 4 .

Fig.-10: Staging of the group 2 patients based eGFR $(n=16)$

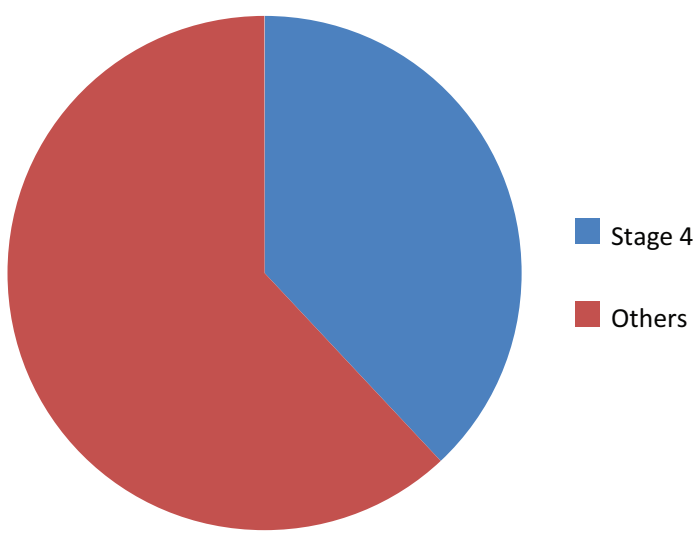

So, the pie diagram shows that $62 \%$ of the populations belong to the stage 4 and the rest are scattered in different stages.

Fig.-11: Percentage of group 2 patients in stage 4 and other

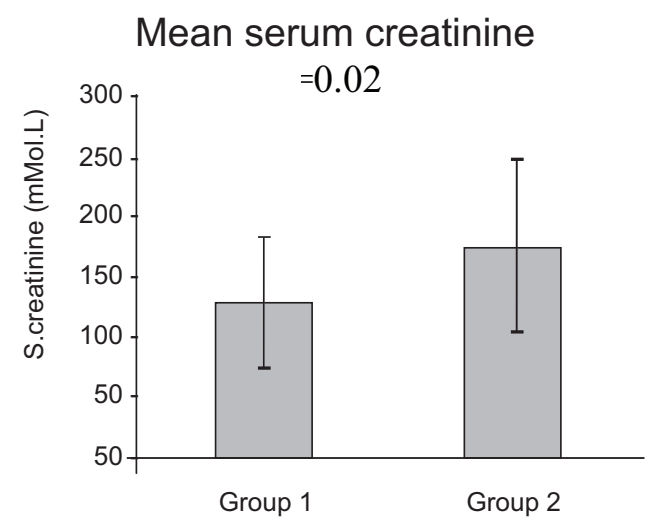

The chart reveals that the difference of serum creatinine in two groups is insignificant.

Fig.-12: Comparison of mean serum creatinine value between group $1 \&$ group 2

\section{Discussion:}

This cross-sectional observational study was carried out on 50 diabetic patients, who fulfilled the inclusion criteria, with an aim to observe the correlation between serum creatinine and urine albumin of diabetic nephropathy patients. The earliest indicator of nephropathy is microalbuminuria. Microalbuminuria means (30-300) mg of albumin are excreted through urine per day. It is considered as the indicator of stage 3 kidney disease. In stage 3 kidney disease the calculated GFR (eGFR) should be between (30-59) $\mathrm{ml} / \mathrm{min}$. As the disease 
progresses, the urine albumin excretion increases over time. In stage 4 , the urine albumin excretion is more than $0.5 \mathrm{~g} / 24$ hours, where the eGFR normally ranges between 15 to $30 \mathrm{ml} / \mathrm{min}^{6}$

Among the study population, the mean age was about 62 years (Figure 1). The male and female ratio was near about equal. $54 \%$ of the patients were male whereas $46 \%$ of the patients were female. Among these 50 patients, 34 patients were included as there was microalbuminuria (Group 1). And the rest 16 patients were included because they had protenuria (Group 2). The study population were distributed according to their clinical presentation (Figure 3). The significant "p" value was found only in case of "Anasarca" (Figure 3). Figure 4 showed that Group 2 patients have developed anasarca more than group 1, which can be explained by the advanced staging of the kidney disease of Group 2 patients.

Figure 6 and 7 reflect that serum creatinine has no virtual correlation with UTP and urine microalbumin respectively as evident by the scattered plot table showing that and the ' $r$ ' value is non-significant.

Then we calculated the eGFR using MDRD equation. Later group $1 \& 2$ patients were distributed to different stages of diabetic nephropathy according to their eGFR (Figure 8 $\&$ Figure 10). Here almost $68 \%$ population belong to the stage 3.The rest belongs to stage 1,2 , and 4 . Similarly, $62 \%$ of population of Group-2 was in the stage 4. Rests were in different groups which is non-coherent with their urine protein excretion.

Thus the study reveals that serum Creatinine is not a good reflector of the staging of the diabetic nephropathy as well as the creatinine based commonly used MDRD equation. It is supported by the study done by Pradeep Kumar Dabla in $2010^{11}$. He mentioned that this equation has recognized limitations, including a tendency to significantly underestimate higher levels of $\mathrm{GFR}^{12}$. Additionally, Parving and colleagues demonstrated that in type 2 diabetic subjects with macroalbuminuria, eGFR had a poor sensitivity for GFR values $<60 \mathrm{~mL} / \mathrm{min}$ per $1.73 \mathrm{~m}^{2} .{ }^{13}$ There are more reports available those show that variation in calibration of the creatinine assay has an adverse impact on the performance of eGFR to estimate GFR, particularly at low levels of serum creatinine ${ }^{15,16}$. So, only Serum creatinine is not enough for staging the diabetic nephropathy and not even for follow up.

To support this evidence, we calculated the mean serum creatinine of both of the groups. The mean serum creatinine of group 1 is $129.062 \mathrm{mmol} / \mathrm{L}$ with a standard daviation of 53.78 while group 2 has a mean serum creatinine $175.94 \mathrm{mmol} / \mathrm{L}$ with a standard daviation of 71.30 . We calculated the ' $\mathrm{P}$ ' value and it was insignificant. So, both of the groups have no significant difference in serum creatinine value but they have a pretty different level of urinary protein excretion. It again points that serum creatinine is not a reliable marker for diabetic nephropathy.

\section{Conclusion:}

Diabetic nephropathy is a common disease in our country. It is, independently, associated with higher mortality and morbidity. Early detection of the disease will help us to formulate a plan for individual patient management. This study showed that if any diabetic patient is screened or a diabetic nephropathy patient is followed up by serum creatinine only, there is a good possibility to miss the proper diagnosis. As it does not reflect the proper staging all the time. All these findings of the study is statistically important to point towards setting an important criteria about correlation between serum creatinine and urine protein. Future more researches should be directed to set up such guideline and also how urine protein can be calculated easily even in rural areas.

\section{References}

1. Available at http://en.wikipedia.org/Diabeticnephropathy (viewed on December 15, 2013).

2. Frier B M, Fisher M.2010. Diabetes mellitus. In: Colledge N R, Walker B R, Ralston S H,eds. Davidson's Principles \& Practice of Medicine. $22^{\text {nd }}$ Edition. London: Churchill Livingstone: page,829831.

3. Available at http://www.caringfordiabetes.com/ Epidemiology-and- pathology/Micro Complications/ EDP_Diabetic_Nephropathy.cfm( Last viewed on December 15,2013) 
4. Available at http://ghf. globalthealthforum.net/ $2011 / 12 / 15$ association-between-diabetic nephropathy-and-hypertension-among-patientsadmitted-in-a-tertiary-hospital-in-dhakabangladesh/\#. UK3PQn8u0ok (Last viewed on Nov 30, 2013).

5. Ritz E, Keller C, Bergis K, Strojek K. Pathogenesis and course of renal disease in IDDM/NIDDM: differences and similarities. Am J Hypertens ,1997;10: 202-207.

6. Available from http://chineseremedy kidney disease. blogspot.com/2013/03/5-stages-of-diabeticnephropathy.html (Last viewed on December 15 ,2013)

7. Available at http://www.cap.org/apps/docs/ committees/chemistry/urine-albumin_ creatinine_ ratio.pdf (Last viewed on December 15, 2013)

8. Allison S J. Diabetes: Estimating GFR and GFR decline in patients with T2DM.Nature Review Nephrology May 2013;246 (9): 1038-1059.

9. Available at https://en.wikipedia.org/wiki/ Renal_function (Last reviewed on November 11,2015)

10. Lascano M E, Poggio E D.,2010. Kidney Function Assessment by Creatinine-Based Estimation Equations. Cleveland Clinic: Centre for Continuing Education (Online) .Available from http:// www.clevelandclinicmeded.com/medicalpubs / diseasemanagement/editorialboard.htm. (Accessed on 30 November 2015)

11. Dabla PK. Renal function in diabetic nephropathy. World Journal of Diabetes. 2010; $1(2): 48-56$.

12. Vervoort G, Willems HL, Wetzels JF. Assessment of glomerular filtration rate in healthy subjects and normoalbuminuric diabetic patients: validity of a new (MDRD) prediction equation. Nephrol Dial Transplant. 2002;17:1909-1913

13. Rossing P, Rossing K, Gaede P, Pedersen O, Parving $\mathrm{HH}$. Monitoring kidney function in type 2 diabetic patients with incipient and overt diabetic nephropathy. Diabetes Care. 2006;29:1024-1030.

14. Coresh J, Astor BC, McQuillan G, Kusek J, Greene T, Van Lente F, Levey AS. Calibration and random variation of the serum creatinine assay as critical elements of using equations to estimate glomerular filtration rate. Am J Kidney Dis. 2002;39:920-929.

15. Stevens LA, Coresh J, Greene T, Levey AS. Assessing kidney function-measured and estimated glomerular filtration rate. N Engl J Med. 2006; 354:2473-2483.

16. Fitch CD, Sinton DW. A study of creatine metabolism in diseases causing muscle wasting. Journal of Clinical Investigation. 1964 Mar;43(3):444. 